\title{
Influence of Job Description on Performance of Health Workers in Public Hospitals: A Case of Mbagathi Hospital, Nairobi City County
}

\author{
Felistus Ndanu Musyoka, Maureen Atieno Adoyo, Musa Oluoch Ongombe \\ School of Medicine and Health Science, Kenya Methodist University, Nairobi, Kenya
}

Email address:

felistusmusyoka506@yahoo.com (F. N. Musyoka),maureenadoyo.kemu@gmail.com (M. A. Adoyo), moluoch123@yahoo.com (M. O. Ongombe)

\section{To cite this article:}

Felistus Ndanu Musyoka, Maureen Atieno Adoyo, Musa Oluoch Ongombe. Influence of Job Description on Performance of Health Workers in Public Hospitals: A Case of Mbagathi Hospital, Nairobi City County. Science Journal of Public Health. Vol. 4, No. 2, 2016, pp. 88-93. doi: $10.11648 /$ j.sjph.20160402.12

\begin{abstract}
Sound human resources management (HRM) practices are essential in strengthening the health systems (HS). HRM practices including use of job description (JD) can transform health workers (HWs) into a productive and motivated workforce that improves healthcare services. Kenyan HS miss this nonmonetary motivator of health workers which is correlated with health worker poor job satisfaction and poor performance in service delivery. This study sought to determine how JD influences the performance of health workers (HWs) using descriptive and exploratory research study design. Questionnaires and key informant guides were completed by sampled technical staff and managers working at Mbagathi hospital. Quantitative and qualitative data was analyzed using descriptive statistics and content analysis respectively. Results indicated that the health service managers were not aware of policies on HRM practices. Clear JD, work plans and task description were available to a little extent $(54.0 \%, 53.2 \%$ and $52.6 \%$ respectively). Established lines of authority were available to a moderate extent (59.3\%). The health workers performance was rated at a mean score of $57.6 \%$ with a standard deviation of $4.2 \%$. The study concludes that HRM practices were poorly implemented in the hospital. Health service managers needed basic training on JD among other HRM practices including and to establish a department that will implement the practices.
\end{abstract}

Keywords: Healthcare Human Resource Management, Job Description, Health Workers Management

\section{Background}

World Health Organization (WHO) defines a health HS as consisting of all organizations, people and actions whose primary intent is to promote, restore or maintain health [1]. A HS is made up of six building blocks namely; service delivery; health workforce; information; medical products, vaccines and technologies; financing; and leadership and governance (stewardship) [2]. Health workforce is all people engaged in actions whose primary intent is to enhance health. HRM is a system, a philosophy, policy and practices that can influence individuals working in an organization. HRM practices include: analysis and designing work, determining human resource (HR) needs, attracting potential employees, choosing employees, teaching them how to perform their jobs and preparing them for the future, rewarding employees, evaluating their performance and creating a positive work environment $[3,4]$.

Job description (JD) is a broad, general and written statement of a specific job that includes duties, purpose, responsibilities, scope and working conditions of a job along with the job title, and the name and designation of the person to whom the employee reports [5]. JDs that clearly set out objectives, responsibilities, authority and lines of accountability are consistently associated with improved achievement of work goal [6]. Lack of employee understanding of work priories, or change of priorities on regular basis makes it difficult for staff to maintain consistent level of productivity. In many cases JDs are too vague or even nonexistent; with unspecified expectations hence managers hire HWs for a particular job and ask them to perform other duties [7]. The role of Clinical Officers is not clearly understood which has resulted in role conflict [8]. 
About 17\% HWs reported unclearly defined job responsibilities that did not match with their knowledge and skills [9]. HWs de-motivators were reported to be lack of JD among other conditions. 54\% of employees stated that they didn't have JDs. Moreover, $44.2 \%$ of those who had JDs considered them as being not update and inappropriate [5].

JDs can provide starting point for developing work plans and are typically general however do not identify which specific responsibility or performance objectives are a priority in given period. Most employees only perform duties listed in their JDs that are a priority [7]. Establishment of clear JDs, along with better in-service training and clearer standards can enhance job satisfaction and compliance with standards among nurses and midwives [10]. It is shown that clear JDs alongside supportive supervision and feedback on performance are consistently associated with improved competence of individual HWs enhanced attainment of work goals $[6,11]$.

\section{Methods}

This was a cross sectional descriptive and exploratory research conducted in Mbagathi Hospital located in Nairobi west, Dagoretti District of Nairobi County. The sample size of 177 respondents was determined using Yamane (1967: $886)$ at $95 \%$ confidence level. Managers and technical staff were purposively and stratified sampled respectively. Data collection was by use of key informant interviews and structured questionnaires. Quality control measures were employed including pre-test, validity and reliability checks.

Permission to conduct research was sought from the university, Nairobi County and relevant authorities at Mbagathi hospital. Respondents consented to participate with confirmation of confidentiality. Collected data was crosschecked for completeness and any missing entries corrected upon completion of each interview. The quantitative data collected was coded, processed and cleaned present inconsistencies and outliers and analyzed using Statistical Package for the Social Sciences (SPSS) version 21.

The qualitative data was analyzed through creating categories, refining them and grouping them into themes and sub-themes before interpretation, presentation and discussion. Relationship between the independent variables and the dependent variable was established using Chi-square tests of association. Findings were presented in the form of text, charts, graphs and tables.

\section{Results}

\subsection{Socio-Demographic Characteristics}

The study response rate was (173) $96.6 \%$. Majority $131(75.7 \%)$ respondents were female and 90(52.0\%) respondents were aged 30-39 years. 43(24.9\%) respondents had worked in the health sector for $\geq 6$ years with most $103(59.5 \%)$ respondents being nurses who had attained diploma level of education.

\subsection{Performance of Health Workers}

General HWs' performance was determined on scores of competence, productivity, availability and responsiveness dimensions evaluated on a 3-level scale coded as disagree (1), undecided (2) and agree (3); summed up and expressed as a percentage of total possible score. The mean performance was $57.6 \%$ with a standard deviation of $4.2 \%$, see Figure 1 (Health worker's performance distribution). The average HWs' competence score was $65.9 \%$ as indicated in Table 1 (Health workers' competence).

HWs' productivity had an average score of $54.6 \%$ and other findings were as indicated in Table 2. (Health workers' productivity). HWs' availability had an average score of $53.5 \%$ and other findings were as indicated in Table 3 (Health workers' availability). HWs' responsiveness had an average score of $56.6 \%$ and other findings were as indicated in Table 4. (Health workers' responsiveness).

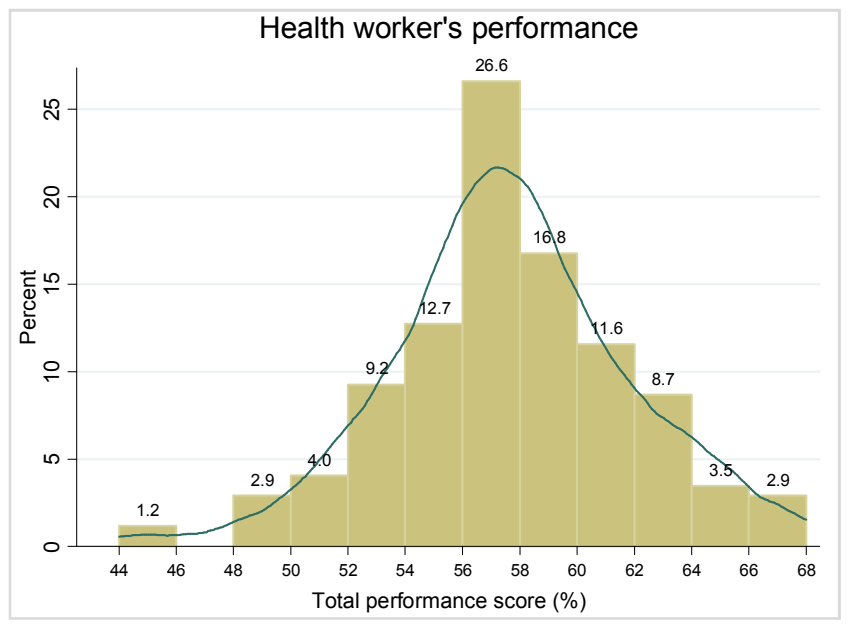

Figure 1. Health worker's performance distribution.

Table 1. Health workers' competence.

\begin{tabular}{|c|c|c|c|c|c|c|}
\hline \multirow{2}{*}{ Competence } & \multicolumn{2}{|c|}{ Disagree } & \multicolumn{2}{|c|}{ Undecided } & \multicolumn{2}{|c|}{ Agree } \\
\hline & $\mathbf{n}$ & $\%$ & $\mathbf{n}$ & $\%$ & $\mathbf{n}$ & $\%$ \\
\hline Confident of ability to do job & 48 & 27.7 & 45 & 26.0 & 80 & 46.2 \\
\hline Mastered skills necessary to perform job & 50 & 28.9 & 76 & 43.9 & 47 & 27.2 \\
\hline Confident about practices & 40 & 23.1 & 88 & 50.9 & 45 & 26.0 \\
\hline Improve knowledge and skills through continuous professional education & 77 & 44.5 & 44 & 25.4 & 52 & 30.1 \\
\hline Attitude toward the care of patients is good & 50 & 28.9 & 48 & 27.7 & 75 & 43.4 \\
\hline Use of knowledge and skills to improve safety of patients & 52 & 30.1 & 77 & 44.5 & 44 & 25.4 \\
\hline Good communication skills & 40 & 23.1 & 88 & 50.9 & 45 & 26.0 \\
\hline Use of available communication technology to support patient care & 85 & 49.1 & 37 & 21.4 & 51 & 29.5 \\
\hline
\end{tabular}


Table 2. Health workers' productivity.

\begin{tabular}{|c|c|c|c|c|c|c|}
\hline \multirow{2}{*}{ Productivity } & \multicolumn{2}{|c|}{ Disagree } & \multicolumn{2}{|c|}{ Undecided } & \multicolumn{2}{|c|}{ Agree } \\
\hline & $\mathbf{n}$ & $\%$ & $\mathbf{n}$ & $\%$ & $\mathbf{n}$ & $\%$ \\
\hline Productivity is measured according to the number of patients attended to & 84 & 48.6 & 75 & 43.4 & 14 & 8.1 \\
\hline Most time is spend attending to patients & 79 & 45.7 & 72 & 41.6 & 22 & 12.7 \\
\hline Skills are suited for the type of work done & 78 & 45.1 & 78 & 45.1 & 17 & 9.8 \\
\hline Much effort is put when on duty & 84 & 48.6 & 68 & 39.3 & 21 & 12.1 \\
\hline
\end{tabular}

Table 3. Health Workers' Availability.

\begin{tabular}{|c|c|c|c|c|c|c|}
\hline \multirow{2}{*}{ Availability } & \multicolumn{2}{|c|}{ Disagree } & \multicolumn{2}{|c|}{ Undecided } & \multicolumn{2}{|c|}{ Agree } \\
\hline & $\mathbf{n}$ & $\%$ & $\mathbf{n}$ & $\%$ & $\mathbf{n}$ & $\%$ \\
\hline Always available when services are required & 70 & 40.5 & 88 & 50.9 & 15 & 8.7 \\
\hline Always fill attendance register & 86 & 49.7 & 69 & 39.9 & 18 & 10.4 \\
\hline Always present during the official working hours & 82 & 47.4 & 79 & 45.7 & 12 & 6.9 \\
\hline Workload accorded is manageable & 82 & 47.4 & 75 & 43.4 & 16 & 9.2 \\
\hline Patient's waiting-time is short & 98 & 56.6 & 61 & 35.3 & 14 & 8.1 \\
\hline
\end{tabular}

Table 4. Health Workers' Responsiveness.

\begin{tabular}{|c|c|c|c|c|c|c|}
\hline \multirow{2}{*}{ Responsiveness } & \multicolumn{2}{|c|}{ Disagree } & \multicolumn{2}{|c|}{ Undecided } & \multicolumn{2}{|c|}{ Agree } \\
\hline & $\mathrm{n}$ & $\%$ & $\mathrm{n}$ & $\%$ & $\mathrm{n}$ & $\%$ \\
\hline Clients satisfied with the quality of services provided & 74 & 42.8 & 84 & 48.6 & 15 & 8.7 \\
\hline Clients satisfied with the timeliness of the services provided & 86 & 49.7 & 80 & 46.2 & 7 & 4.0 \\
\hline Complaints from stakeholders are rare & 75 & 43.4 & 80 & 46.2 & 18 & 10.4 \\
\hline Always cooperate with other health workers & 81 & 46.8 & 82 & 47.4 & 10 & 5.8 \\
\hline Clearly know who is served daily & 84 & 48.6 & 74 & 42.8 & 15 & 8.7 \\
\hline Always willing to address the clinical and emotional demands of the patients & 86 & 49.7 & 73 & 42.2 & 14 & 8.1 \\
\hline Know what is expected at work & 44 & 25.4 & 42 & 24.3 & 87 & 50.3 \\
\hline
\end{tabular}

\subsection{Job Descriptions on Performance of Health Workers}

There was no significant association between JD dimensions and performance dimensions, see Table 5 (Job description and performance of health workers).

Table 5. Job Description and Performance of Health Workers.

\begin{tabular}{llllll}
\hline Job description dimensions & & Competence & Productivity & Availability & Responsiveness \\
\hline \multirow{2}{*}{ Clear job descriptions } & $\mathrm{r}$ & -0.068 & -0.062 & 0.112 & -0.062 \\
& $\mathrm{p}$ & 0.374 & 0.421 & 0.142 & 0.417 \\
Established lines of authority & $\mathrm{r}$ & 0.037 & -0.118 & 0.135 & -0.073 \\
& $\mathrm{p}$ & 0.633 & 0.123 & 0.076 & 0.339 \\
Work plans & $\mathrm{r}$ & -0.045 & -0.084 & 0.105 & -0.039 \\
& $\mathrm{p}$ & 0.558 & 0.273 & 0.17 & 0.612 \\
Task description & $\mathrm{r}$ & -0.008 & -0.001 & -0.036 & 0.004 \\
& $\mathrm{p}$ & 0.912 & 0.994 & 0.642 & 0.956 \\
\hline
\end{tabular}

$\mathrm{r}$ - spearman rho; $\mathrm{p}$ - $\mathrm{p}$-value

\subsection{Clear Job Description}

$55(31.8 \%)$ of the thought that clear JD occurs to a little level while $26(15 \%)$ felt that they have JDs which are clear to a great level. Overally, clear JD occurred to a little level ( median $=1)$.

\subsection{Established Lines of Authority in Job Descriptions}

$45(26.0 \%)$ thought that established lines of authority occurs to a moderate level while $25(14.5 \%)$ felt that there were no established lines of authority at all. In overall, established lines of authority was used to a moderate extent $($ median $=2)$.

\subsection{Work Plans in Job Descriptions}

$60(34.7 \%)$ thought that work plans occurs to a little level while $18(10.4 \%)$ of the respondents felt that work plans are there to a very great level. In overall, work plans was used to a little extent $($ median $=1)$.

\subsection{Task Description in Job Descriptions}

$45(26.0 \%)$ thought that task description are not available at all while $20(11.6 \%)$ felt that there are task descriptions in the JDs to a very great level. In overall, task description was also used to a little extent (median $=1)$. 


\subsection{Challenges to Health Service Managers on HRM Practices}

There were no trainings on HRM practices including support supervision. The health service managers were not aware of any existing policies on HRM. HRM practices were conducted through health administrative offices. This depicts a non-involvement of HWs on HRM practices which could be detrimental to their motivation thereby significantly hampering their productivity.

\section{Discussion}

In the study, majority $131(75.7 \%)$ respondents were female similar to $60 \%$ female proportion in the national HS [12] and studies done in Nairobi (62.0\%) [13] among health care workers. Most 90(52.0\%) respondents were aged 30-39 years and $43(24.9 \%)$ respondents had worked in the health sector for $\geq 6$ years. Similar age characteristics were observed in a different study in Kenya where $\geq 60 \%$ nurses were 41 years and above [14]. Most 103(59.5\%) respondents were nurses who had attained diploma level of education similar to proportion of nurses in Kenya nearly $60 \%$ [12].

\subsection{Performance of Health Workers}

The mean performance of HWs was $57.6 \%$ with a standard deviation of $4.2 \%$. The average HWs' competence score was $65.9 \%$ similar to findings in a study conducted in Uganda [15]. Contrary findings indicated that high percentage of HWs were unable to work to the expected standard because of lack of training and performance management [16]. Another study in Kenya concluded that health provider competency at performing basic, life-saving skills was quite low and that their tendency to refer patients with complications were all too common [17].

The HWs' productivity score had an average of $54.6 \%$. This was similar to findings in Zanzibar where on average HWs spent three-fifths (61\%) of their observed on-the-job time doing productive activities, primarily providing direct care for patients and also spent more than one fourth (27\%) of the observed time doing unproductive activities, mostly waiting for patients [18]. This can be explained by assertion that Kenya has embarked on improved institutional and health worker productivity; and a performance structure that is appropriate in delivering health care and ensures an equitable distribution of HWs in facilities [14].

HWs' availability had an average score of $53.5 \%$. Similarly, despite the fact that policies are in place to ensure the availability of HWs, less than half of HWs were present in their place of work and active at the time of survey $[9,19,20]$. Contrary, most respondents interviewed reported that the health providers were available in their place of work and that they were productive [16].

HWs' responsiveness had an average score of $56.6 \%$. The responsiveness score was below $73 \%$ of a study done in Ethiopia where respondents felt that provider's empathy was good and $83 \%$ rated non-verbal communication as good [17].
Responsiveness defines how well the HS meets the legitimate expectations of the population [16]. In Ethiopia there was a relatively high level of satisfaction $(80 \%)$ of patients with health services they received mainly waiting time and courtesy of staff [17].

\subsection{Job Description Practiced on the Performance of Health Workers}

There was no significant association between use of JD dimensions and performance dimensions. On the contrary, HWs need clear JDs that outline what is expected of them, what is allowed and what skills they require to do their jobs [21]. These may be national documents that can be adapted in the workplace. A key benefit of JDs is that they enhance employee productivity. In some cases, lack of a JD causes employees to emphasize the wrong aspects of their jobs. A written JD should not only include the tasks an employee is expected to perform but also a ranking of importance of each duty. JDs prevent employees from misunderstanding which work is theirs, reducing instances of work not being done because someone thought the duty was not in her JD or work being duplicated because two employees assumed they were responsible for a task [22]. Employees who know not only what they're supposed to do but also what their peers' responsibilities are become stronger team members. Although many health care workers had JDs, the performance indicators and standards were not clearly defined and known to all workers and managers [23].

Existing JDs were not clear and never reviewed. Similarly, HWs are often not provided with the JD or outdated JDs with poorly defined responsibilities [9]. Contrary views were made in the DHMT survey in which it was observed 61 percent of districts used JD for staff appraisal [24]. In a survey of 856 nurses and midwives in five provinces in Indonesia found that $47.4 \%$ nurses and midwives did not have written JDs, $39.8 \%$ were engaged in work other than nursing care or midwifery and $70.9 \%$ had not received inservice training for the past three years [25].

Established lines of authority were used to a moderate extent though they were not very clear. Typically in an hospital there are dual lines of authority since in an established group practice the medical staff seldom exist as a formal entity but instead the physicians own the enterprise since they are basically focused on providing patient care thus their fundamental loyalty is to their patients and their accountability is to their professional colleagues meaning they are not concerned primarily with the success of the organization, nor do they acknowledge its legitimate power and authority [26]. Contrary, 69.6\% hospitals had Nurse Executive line authority for nurse staffing [27].

Work plans were lowly used and in some cases not available. On the contrary, $52 \%$ of districts in the DHMT survey used work plans [24]. In Sudan, records of the ministry of health and other health care organizations show no documentation for planning documents in the domain of the health workforce [28].

Task description was used to a little extent similar to a case 
where even though Clinical Officers are important service providers their role is not clearly understood, which has resulted in role conflict [8]. Further, from a total of 747 respondents, 17 per cent stated that their job responsibilities were not clearly defined, or that their job responsibilities did not match with their knowledge and skills [9].

\section{Conclusion}

The HWs at the hospital were not able to clearly know what is expected of them, what is allowed and what skills they require to do their jobs. This increased cases of misunderstanding on which work is theirs and reduced instances of work being done. The HWs performance was averagely rated, in conjunction with unclear JDs.

\section{Limitations of the Study}

The researcher relied on self-report performance indicators hence bias was a possibility since individuals are likely to exaggerate their performance.

\section{Acknowledgments}

The authors of this publication "Influence of Job Description on performance of Health Workers in public hospitals: A case of Mbagathi Hospital, Nairobi City County" would like to thank Kenya Methodist University for supervision and Exactitude Research Consultants (Ltd) for data management services.

\section{References}

[1] WHO, Everybody's Business: Strengthening Health Systems to Improve Health Outcomes: Who's Framework For Action.: World Health Organization, 2007.

[2] Flavia Senkubuge, Moeketsi Modisenyane, and Tewabech Bishaw, "Strengthening health systems by health sector reforms," Global Health Action, vol. 5, no. 23568, 2014.

[3] Abbas Daneshkohan et al., "Factors Affecting Job Motivation among Health Workers: A Study From Iran," Global Journal of Health Science, vol. 7, no. 3, pp. 153-160, 2015, DOI: http://dx.doi.org/10.5539/gjhs.v7n3p153.

[4] A. Nasiripour, M. AfsharKazemi, and A. Izadi, "Effect of different HRM Policies on Potential of employee Productivity," Research Journal of Recent Sciences, vol. 1, no. 6, pp. 45-54, 2012.

[5] Lynne Miller Franco, Sara Bennett, and Ruth Kanfer, "Health sector reform and public sector health worker motivation: a conceptual framework.," Social Science \& Medicine, vol. 54, no. 8, pp. 1255-1266, April 2002.

[6] WHO, "The World Health Report 2006: Working together for health," Geneva, 2006.

[7] M O'Neil and S Reimann, "Strengthening human resource management to improve health outcomes," eManager, vol. 1, pp. 1-17, 2009.
[8] Patrick Mbindyo, Duane Blaauw, and Mike English, "The role of Clinical Officers in the Kenyan health system: a question of perspective," Human Resources for Health, vol. 11, no. 32, July 2013.

[9] Society for Local Integrated Development Nepal (SOLID Nepal) and Merlin Nepal., "Barriers to Effective Policy Implementation and Management of Human Resources for Health in Nepal: Health Workforce Performance and Accountability (Availability, Competencies, Responsiveness and Productivity)," Lalitpur, Nepal, 2012.

[10] WHO, "Making the Most of Existing Health Work Force," Geneva, 2006.

[11] Scholastika N Iipinge, Kathe Hofnie, Lucille van der Westhuizen, and Monika Pendukeni, "Perceptions of about conditions of service: a Namibian case study..," EQUINET discussion paper No. 352006.

[12] Harrison Kiambati, Caroline Kiio, and John Toweett, "Understanding the Labour Market of Human Resources for Health in Kenya.," Geneva, Working Paper 2013.

[13] David Ojakaa, Susan Olango, and Jordan Jarvis, "Factors affecting motivation and retention of primary health care workers in three disparate regions in Kenya," Human Resources for Health, vol. 12, no. 33, June 2014.

[14] Alice Mutungi et al., "Kenya: Assessment of Health Workforce Competency and Facility Readiness to Provide Quality Maternal Health Services," Bethesda, MD: University Research Co., LLC (URC)., 2008.

[15] George William Lutwana, J. H. Roos, and B. L. Dolamo, "The Performance of Health Workers in Decentralized Services in Uganda," Universtiy of South Africa, Pretoria, PhD Thesis 2011.

[16] Asigele Oswald, "The Effect of Working Environment on Workers' Performance: The Case of Preproductive annd Child healthcare Providers in Tarime District," 2012.

[17] Berhanu Feysia, Christopher Herbst, and Wuleta Lemma, The Health Workforce in Ethiopia: Addressing the Remaining Challenges.: World Bank Publications, 2012.

[18] Paul Ruwoldt and Philip Hassett, "Zanzibar Health Care Worker Productivity Study: Preliminary Study Findings," Zanzibar, 2007

[19] Jacinta Nzinga, Patrick Mbindyo, Lairumbi Mbaabu, Ann Warira, and Mike English, "Documenting the experiences of health workers expected to implement guidelines during an intervention study in Kenyan Hospitals," Implementation Science, vol. 4, no. 44, pp. 1-9, 2009.

[20] Jacinta Nzinga, Lairumbi Mbaabu, and Mike English, "Service delivery in Kenyan district hospitals - what can we learn from literature on mid-level managers?," Human Resource for Health, vol. 11, no. 10, February 2013.

[21] John Ehiri, Maternal and Child Health: Global Challenges, Programs, and Policies.: Springer Science \& Business Media, 2009.

[22] Sam Ashe-Edmunds, "The Effect of Job Descriptions on Employee Performance," Hearst Newspapers, LLC, Jul 2015. 
[23] George William Lutwama, Janetta Hendrika Roos, and Bethabile Lovely Dolamo, "Assessing the implementation of performance management of health care workers in Uganda," BMC Health Services Research, vol. 13, no. 355, September 2013.

[24] P.M. Ndavi, S. Ogola, P.M. Kizito, and K. Johnson, "Decentralizing Kenya's Health Management System: An Evaluation," Calverton, Maryland, USA:, Kenya Working Papers 2009.

[25] WHO, "World Health Report: Shaping the Future," Geneva, 2002.
[26] Robert J. Taylor and Susan B. Taylor, The AUPHA Manual of Health Services Management. Maryland, USA: Jones \& Bartlett Learning, 1994.

[27] Chuan-Fen Liu et al., "Relationship between Line Authority for Nurse Staffing and Patient Care Cost," iHEA 2007 6th World Congress: Explorations in Health Economics Paper 2007.

[28] Elsheikh Badr, "Human Resources for Health (HRH) Strategic Work Plan for Sudan (2008-2012)," National Human Resources for Health Observatory \& WHO, Strategic Plan 2007. 